Original Research Paper

\title{
Efficacy of Numeric Keypad for Computer Illiterates in Rural ICT
}

\author{
${ }^{1}$ Pallab Dutta, ${ }^{1}$ Mahesh Kumar, ${ }^{1}$ Sridharan, B. and ${ }^{2}$ Vipin Tyagi \\ ${ }^{I}$ Centre for Development of Telematics, Electronic City, Bangalore, India \\ ${ }^{2}$ Centre for Development of Telematics, Mehruli Road, New Delhi, India
}

\author{
Article history \\ Received: 21-02-2015 \\ Revised: 08-09-2015 \\ Accepted: 18-11-2015 \\ Corresponding Author: \\ Pallab Dutta \\ Centre for Development of \\ Telematics, Electronic City, \\ Bangalore, India \\ E-mail: pallab@cdot.in
}

\begin{abstract}
The world has a vast population of illiterate people who cannot read and write. There are globally about 781 million adults today who fall into this category of illiterate population. The number is even higher for computer illiterates, as not all literate masses qualify to be computer literate due to various compelling factors prevailing. There has been a lot of focus in recent times by both governmental and nongovernmental agencies to extend the proliferation of ICT among computer illiterates, especially in the rural areas. This focus is prevalent both worldwide and as well as in India. India has around $37 \%$ of world's illiterate population. One of the major bottleneck and hindrance towards achieving penetration objective is due to the lack of a suitable Human Computer Interface (HCI) system addressing the specific needs of the computer illiterate section. In this study, we discuss the various aspects of input devices for this segment. We analyze the efficacy of a simplified numeric keypad as a $\mathrm{HCI}$ in an information dissemination system for computer illiterates specifically in the context of rural area usage.
\end{abstract}

Keywords: Input Device, Keypad, Computer Illiterate, Rural Area, Cognitive Ability

\section{Introduction}

There has been an unprecedented expansion and proliferation of Information and Communication Technology (ICT) and Internet in particular, since last couple of decades or so. ICT is used across many applications ranging from e-commerce, e-governance, elearning, video-conferencing, agriculture etc. There is no single concise definition of ICT in the literature but diverse terms are used to define ICT. The definition of ICT is context and application area specific. In (Rouse, 2005), ICT is described as an umbrella term that includes any communication system consisting of radio, television, cellular phones, computer and network hardware and software etc. and also various services and applications associated with them. With present technological advancements, information and communication technologies go hand in hand in a converged paradigm towards offering diverse applications and services to the users. ICT tools can be used to explore, extract, analyze, exchange and present information conveniently, effectively, objectively without socio-cultural and economic discrimination and bounds. Many countries around the world have established organizations for the promotion of ICTs as a means to bridge the digital divide. According to the European Commission, the importance of ICTs lies less in the technology itself than in its ability to create greater access to information and communication in underserved populations. Digital India (DeitY, 2014) is a programme to transform India into a digitally empowered society and knowledge economy with Visions of Digital Infrastructure as a Utility to every citizen, Governance and services on demand, Digital empowerment of citizens. In such programmes, appropriate ICT solutions play pivotal role towards providing technological backbone and practical implementation enabler. Here, in this context, it is imperative to interpret the term 'literacy'. There are many definitions of literacy too; however the most accepted definition is as given in Merriam-Webster's Collegiate Dictionary. It is defined as "ability to read and write". There are globally about 781 million adults today who fall into this category of illiterate population (UNESCO, 2014). In recent times, in the context of ICT, the term 'computer literacy' is coined and is often used. Computer literacy is the ability to use a conventional desktop computer for performing basic tasks. There are many modules and sub-systems of ICT, namely computing unit, Input/Output devices, network interface, software applications etc. Towards 
the success of any ICT initiative intended for under privileged illiterate masses, it is extremely critical to have a user friendly mechanism to use the system, without which no ICT program can be successful on the ground. There are many gesture based techniques (U1 Haq et al., 2011; Juan et al., 2011; Nitish and Unnikrishnan, 2012), but these are not suitable for people with lower level of cognitive abilities. The design of input devices considering the cognitive abilities of intended users and prevailing rural eco system is major challenge. In this study we discuss and scrutinize various aspects of HCI and input devices for computer illiterates in rural ICT and also analyze the suitability of a simplified numeric keypad in this context and use-case scenario. A simplified numeric keypad specifically designed according to our developed User Interface (UI) and here we assess the suitability of the same in the intended context.

Rest of the paper is structured as follows: section II of this study discusses Illiteracy and cognitive abilities, computer illiteracy and the related work done. Requirements (to be met) of input devices in Rural ICT are listed in section III, the details of numeric keypads along with the differences with keyboard and mouse are described in section IV. Details of experimentation towards determination of usability of simplified numeric keypad are given in section $\mathrm{V}$ with experimental results in section VI. Section VII gives future trends in HCI and conclusion in section VIII.

\section{Illiteracy, Computer Illiteracy and Cognitive Abilities}

There are five levels of functional literacy that have been identified (VanLinden and Cremers, 2008). Level 1 is the lowest level. People with very poor literacy skills belong to this level. They may have some alphabetic knowledge, but they cannot use this knowledge in a functional manner. Next is Level 2 persons who can process only simple, short and clear text material. They cannot deal with complex tasks. Persons belonging to level 3 satisfy the minimum requirements for coping with the demands of everyday life and can work in complex situations and can solve complex problems. Levels 4 and 5 describe persons who demonstrate ability of higher information processing and problem solving skills in more complex situations.

Functionally illiterate persons lack sufficient reading, writing and calculation skills which are needed for successful, independent, dignified living. Functionally illiterate persons also do not possess the skills required to work with intelligent machines/computers, understand instructions and use ICT. Researchers have identified a variety of cognitive skills, whose underdevelopment poses barriers for realizing useful interaction on ICT applications (Medhi et al., 2010; Eshet-Alkalai, 2004). In order to facilitate illiterate segment, UIs become increasingly graphical in nature. Hypermedia, an extension of the term hypertext, is a nonlinear medium of information which includes graphics, audio, video, plain text and hyperlinks and this presents complex navigational paradigms through multiple sources of information. The effective use of these environments requires basic cognitive skills (Medhi et al., 2010). It is an established hypothesis in the domain of cognitive science that illiterate users have different cognitive skills for abstraction, decoding and reasoning in comparison with literate users (Medhi et al., 2010) and hence can be logically inferred that literacy is correlated with general cognitive skill development. Illiteracy in this context would mean the lack of textual literacy. It has also been suggested that literate people acquire skills to organize and process information towards comprehension and reasoning in more efficient ways compared with nonliterate people (Luria, 1976; Manly et al., 2003). Thus, along with basic literacy (reading and writing skills), educated literate people seem to acquirehighercognitive skills and aptitude for relevant information processing (Medhi et al., 2010) more efficiently and felicitously. Hence in order to design a HCI and specifically an input device, meant for functionally illiterate persons, more knowledge and analysis is needed on the cognitive skills of this user group. Along with illiteracy, the rural ecosystem plays very crucial and challenging proposition for the ICT system developers of this segment. Both feelings of anxiety and lack of self-efficacy of illiterate (\& computer illiterate) persons play a decisive role during the use of ICT (Czaja et al., 2006). Computer anxiety caused, eitherby the inability to read and write, inability to use computer accessories or due to any other reasons (Taveira and Choi, 2009) (such as aging, novice etc) make functionally computer illiterate persons heavily dependent on human intermediates for some form of help and mediation. The feeling of being autonomous and independent is diminished to a large extent by this dependency; also this lowers self-esteem and self-efficacy. Hence this population of computer illiterates lacks the self-confidence to produce designated levels of performance and that in turn adversely affect their lives. The aim is to design and develop a HCI and an input device that successfully and effortlessly overcomes logizomechanophobia among computer illiterates. This enables spontaneous imbibing of technology and works as an impetus towards narrowing down digital divide.

\section{Requirements and Design Challenges of Input Devices for Computer Illiterates in Rural ICT}

\section{Language Agonistic}

Majority of the rural population consists of illiterates who know only their local language. They can't speak or write in English. They can barely read and write in their local language. Hence input devices should take care for language illiteracy of rural people and should have enough pictorial representation to aid the users. 


\section{Ruggedness}

Since rural people being novice user of ICT devices, they handle it roughly and improperly. The eco system prevailing in rural areas, especially in the developing countries are largely challenging in terms of power outages, erratic grid power conditions, high temperature ranges, varying humidity, dusty environment etc. Hence, input devices should be robust enough to bear rough handling of rural users as well as withstand the rural eco system challenges.

\section{Usage Instructions}

Since rural people are new to such devices, some instructions or training for usage is required to be given to them so that they can use those devices properly. Illiterate or rural people are weaker in the processing of spoken information, have lower cognitive ability of understanding and following instructions, have less cognitive processing speed as compared to literate people. Hence, input device should be such that user should be able to use it with fewer instructions or training of usage (VanLinden and Cremers, 2008).

\section{GUI Compatibility}

Different input devices take user inputs in different formats. For example, keyboard takes input in text and symbol format, mouse takes input in the form of its 2D spatial displacement and few click buttons. Some input devices like joysticks can give input in the form of 3D spatial movement or position. In order to utilize the inputs for best user experience, it is necessary to improve the user interface on the screen with which user is dealing. For example, best use of keyboard is best suited for DOS like environments where input and outputs are in text format. In order to provide rural illiterate people all the information which can be in text or graphical format, it is necessary that user interface is graphical and input device should be able to deal with that interface easily (Medhi et al., 2011).

\section{Input Sensitivity}

Being novice user of ICT system, rural people are slow at giving inputs to the system. Hence, input device should have input sensitivity which matches with the speed of rural people, so as to avoid unintended inputs. For example, keyboard's repeat rate may be too high to use by rural people. This will lead to repeated input of same key if key is pressed longer. Similarly if mouse pointer movement sensitivity is too high, cursor covers larger distance for small mouse movement (Chang, 2008; VanLinden and Cremers, 2008).

\section{Power Constraints}

Rural areas have irregular electricity supply. Some areas get electricity for limited hours per day. Hence when designing an ICT system for rural areas, this should be taken care of. To overcome power supply problem, it may be required to run devices on battery supply. So, the devices should have as much low power requirement as possible. They should be power efficient (Chang, 2008).

Cost

Cost is very important factor in designing input devices for rural ICT (Chang, 2008) and shall be low/comparable with that of conventional input devices.

\section{Numeric Keypads and the Differences with Keyboard and Mouse}

During development of a rural information dissemination system, we have developed a simplified numeric keypad that collaboratively work with our designed UI and provided synergic result in terms of ease of usage to the end users (Table 1). The numeric keypad is designed keeping in mind the requirements of input devices as discussed in the previous section. The details of the keypad are as follows.

Total number of keys: 19 with following keys. Refer Fig. 1:

- Number keys from 0 to 9

- Home

- Back

- Ok (Enter)

- Up

- Down

- Print

- Help

- Easy Card

- Clear

\section{Physical Specifications}

- Width $\times$ Height: $14 \times 16 \mathrm{~cm}$

- Button Size (Except OK): $2.3 \times 2.3 \mathrm{~cm}$

- OK button size: $2.3 \times 5.3 \mathrm{~cm}$

\section{Other Features}

- Pictorial representation as well as Hindi names of special purpose keys

- Braille representation of all keys for blind users

- All buttons are mapped to separate items in the web page (UI)

- Proper contrast colors in button for better visibility

- Appropriate font size

- LED indication

- Tactile effect 


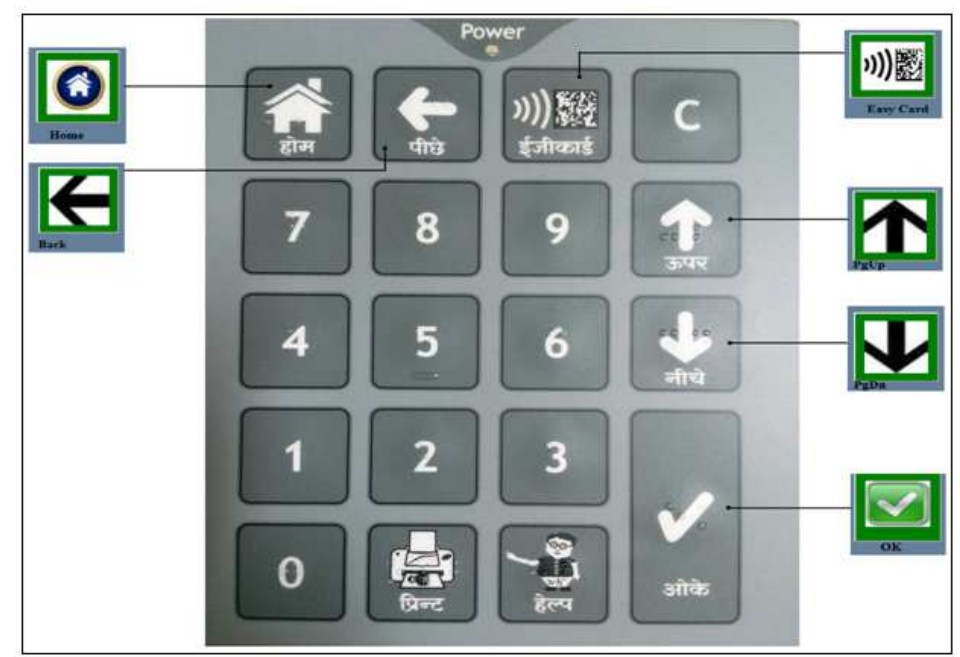

Fig. 1. Numeric keypad developed

Table 1. Difference between keyboard, mouse and numeric keypad

\begin{tabular}{|c|c|c|}
\hline Keyboard & Mouse & Numeric keypad \\
\hline $\begin{array}{l}\text { Rural people are illiterate, they don't know English. } \\
\text { cannot use standard keyboard. }\end{array}$ & $\begin{array}{l}\text { Lesser options for using than keyboard } \\
\text { and num keypad }\end{array}$ & $\begin{array}{l}\text { Provides lesser buttons than Hence } \\
\text { keyboard. }\end{array}$ \\
\hline It is difficult to map regional languages to & Difficult to map mouse movement to & Less confusion, easier to \\
\hline keyboard buttons and also difficult to use. & cursor movement & understand than keyboard \\
\hline $\begin{array}{l}\text { Many local languages have different scripts which } \\
\text { are not included in standard Unicode set, rendering } \\
\text { those scripts requires support from OS. }\end{array}$ & Difficulty in how to hold mouse in hand & $\begin{array}{l}\text { GUI should be modified to use } \\
\text { numeric keypad. }\end{array}$ \\
\hline $\begin{array}{l}\text { More buttons make more confusion and difficult to } \\
\text { understand \& remember the use of all of them }\end{array}$ & $\begin{array}{l}\text { Left and right click buttons are very close } \\
\text { and are to be clicked by fingers of the same } \\
\text { hand. Hence there is difficulty and confusion } \\
\text { while pressing desired button. }\end{array}$ & $\begin{array}{l}\text { Difficult to use when input is in } \\
\text { alphabets. }\end{array}$ \\
\hline $\begin{array}{l}\text { Buttons are placed very close to each other, hence } \\
\text { more chances of mistakes while pressing a desired } \\
\text { button. }\end{array}$ & $\begin{array}{l}\text { Using mouse properly requires practice. } \\
\text { Rural people don't own computers, hence } \\
\text { have less practice. } \\
\text { Timing of double click, even single click is } \\
\text { is difficult for new users due to mouse } \\
\text { movement during click. }\end{array}$ & $\begin{array}{l}\text { Very less training is required } \\
\text { since people are familiar with } \\
\text { mobile and calculator keypads. }\end{array}$ \\
\hline
\end{tabular}

\section{Experiment}

An experiment is carried out to assess the usability of our designed numeric keypad vis-à-vis conventional keyboard and mouse. This setup for the experiments was as follows.

Keypad, Keyboard and mouse (one at a time) were given to the end users to navigate in our developed UI. Prior brief training/demo is given to the end users. Users were chosen to be illiterate and hence were also computer illiterates. Few of them knew how to read and write in their respective local languages but none of them had exposure to English language. All of them were mobile users and were comfortable with identification of 0 to 9 numeric. A total of 25 users were called and all were given brief training on how to use the UI using the numeric keypad/keyboard/mouse. Out of 25 users, 18 were man and 7 were women. All in the age group between
25 years to 40 years. After brief training they were given activity of navigating through our UI and towards some specific task. They were also given the activity of navigating the UI using mouse and keyboard separately. In order to reduce their anxiety level and make them comfortable, they were given orientation and were specifically briefed about the objective of the experiment and do not have any bearing on their employment and livelihood.

\section{Experimental Results and Discussion}

The experiment was carried out with illiterate users, the results of the experiment is captured in the Table 2. The details of the users and the time taken by each users to navigate through are captured and shown in the Table 2 above. The mean (also known as average), is obtained by dividing the sum of observed values by the number of observations, $n$. Although data points fall above, below, 
or on the mean, it can be considered a good estimate for predicting subsequent data points. The formula for the mean is given below as Equation 1:

$$
\bar{x}=\frac{\sum_{i=1}^{n} x_{i}}{n}
$$

Where:

$$
\begin{aligned}
\bar{x} & =\text { Mean } \\
n & =\text { Total number of items } \\
x_{i} & =\text { Individual values }
\end{aligned}
$$

The standard deviation gives an idea of how close the entire set of data is to the average value. Data sets with a small standard deviation have tightly grouped, precise data. Data sets with large standard deviations have data spread out over a wide range of values

The formula for standard deviation is given below as Equation 2. Standard deviation is the square root of variance:

$$
\sigma=\sqrt{\frac{1}{n-1} \sum_{i=1}^{n}\left(x_{i}-\bar{x}\right)^{2}}
$$

Where:

$$
\begin{aligned}
\bar{x} & =\text { Mean } \\
\sigma & =\text { Standard Deviation } \\
\mathrm{n} & =\text { Total number of items } \\
\mathrm{x}_{\mathrm{i}} & =\text { Individual values }
\end{aligned}
$$

The illiterate users were finding it extremely difficult to use the mouse. Users were unable to control cursor properly. Also clicking on a desired itemon the screen was extremely inconvenient for them even after repeated attempts and assistance. The mean and standard deviations of time taken by the users to navigate using the conventional keyboard and simplified numeric keypad are shown in the Fig. 2 and 3 respectively. The average time taken to navigate through our UI by using the developed numeric keypad is $34.12 \mathrm{sec}$ and using conventional keyboard is 49.76 sec. The standard deviation of time taken by using keypad is $4.0 \mathrm{sec}$ and by using keyboard is $4.39 \mathrm{sec}$. As the users in this case are illiterates, it has not been possible to capture the 'usability' or 'easiness' factors quantitatively, the cognitive abilities of these set of users are not upto the level to define 'usability' factor quantitatively. We have captured the number of errors/mistakes done by the users in each case and then derive the 'easiness' factor (represented by $\alpha$ ) using Equation 3:

$$
\infty_{i}=1-\frac{e_{i}}{e_{m}} \text { for } i=1 \text { ton }
$$

Where:

$$
\begin{aligned}
\propto= & \text { Easiness factor } \\
n= & \text { Number of users } \\
e_{i}= & \text { Mistake/error made while navigation by a } \\
& \text { particular user using either keyboard or keypad } \\
e_{m}= & \text { Maximum error considering both numeric keypad } \\
& \text { and keyboard }
\end{aligned}
$$

For user1, by substituting the values in Equation 3, easiness factor while using keyboard is 0.6 and while using numeric keypad is 0.8 .

The Fig. 4, shows the easiness factor of the users for keypad and keyboard.

The general feedbacks as collected during the survey suggest that the users are more comfortable and face less mental anguish while using the numeric keypad as compared to the conventional keyboard. Also during the experiment it is evidently clear that illiterate users are familiar with the numeric, this is mainly due to the penetration of mobiles cutting across literacy levels and all other demographic parameters. Hence the numeric keypad that is designed in conjunction with the UI, eases out the usage by computer illiterates. The tactile effect that is provided in the keypad helps the users by providing a mechanical feedback about the key being pressed and this avoids multiple times pressing the key or applying extra undue force in the keypad. This in effect increases the life of the keypad.

\section{Future Trends in HCI and Input Devices}

\section{Speech Interaction with Audio/Visual Feedback}

Rural/illiterate people cannot handle most of the currently available input devices. Most of them cannot write and hence cannot type even local language. So it's better to utilize their speaking capability. Using mic as input device, their voice commands can be recognized using speech recognition. Once command is recognized, proper action will be taken and result is provided to the user either with voice announcements or in visual format.

\section{Advanced Gesture Recognition}

One of the most intuitive way humans interact among themselves is using gestures; so human interactions with computing systems using gestures is the most natural extension of the same. Hand gesture is the commonly used natural way of humans tends to express them while communicating (Dutta et al., 2013). Gesture recognition can be seen as a way for computers to begin to understand human body language, thus building a richer bridge between machines and humans. Depth sensing, 3D gesture Recognition based input devices may in future becomes really useful to the users especially illiterate users. 


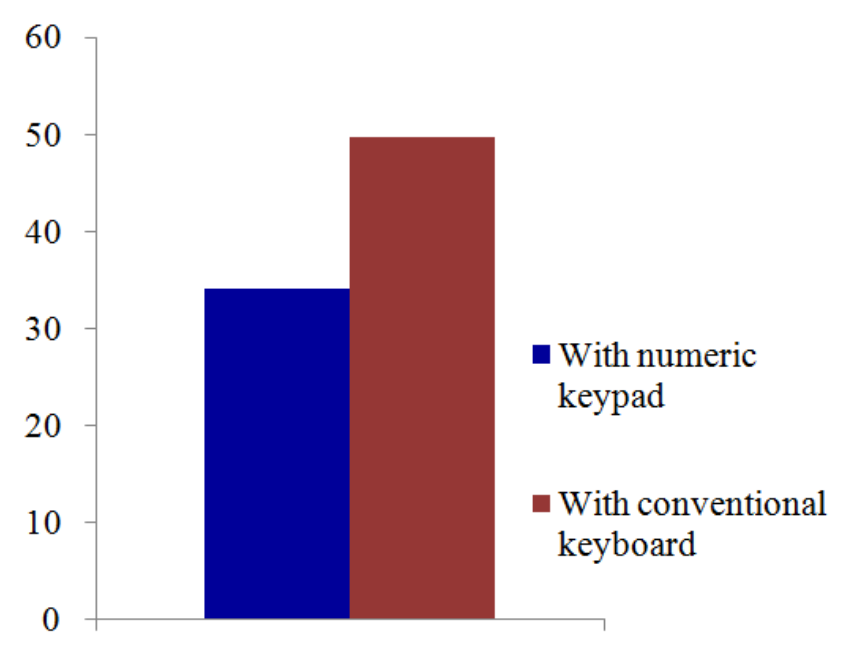

Fig. 2. Mean of navigation time

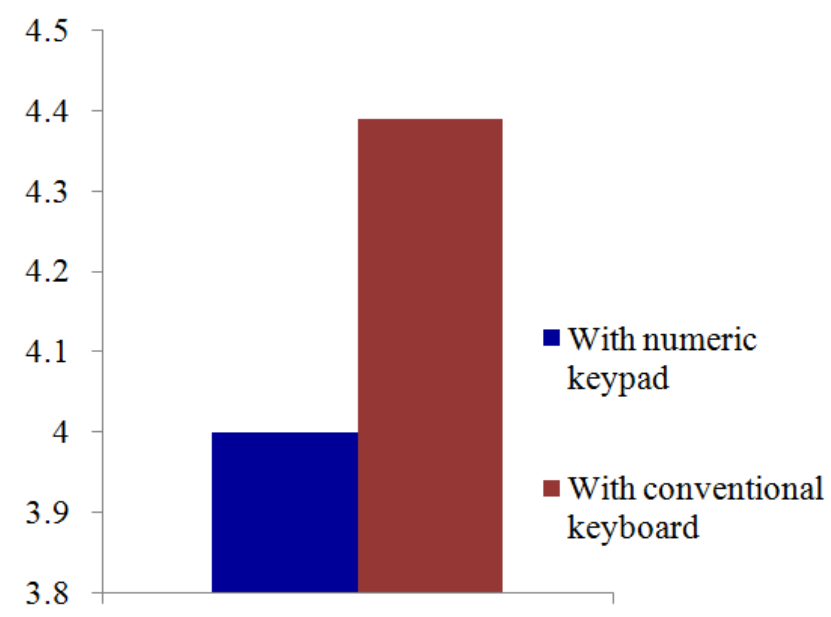

Fig. 3. Standard deviation of navigation time

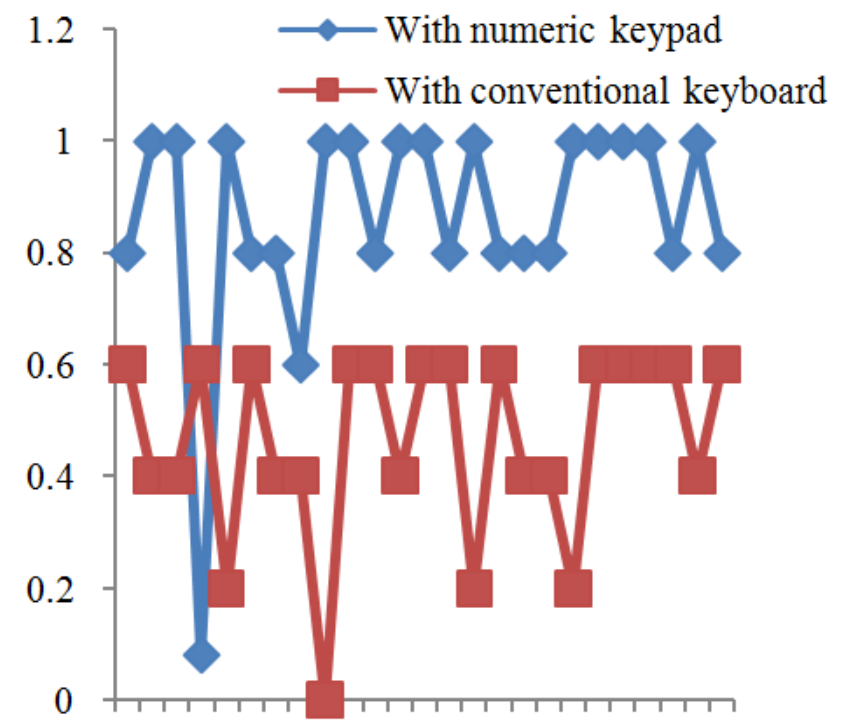

Fig. 4. Easiness factors of users (Keypad and Keyboard) 


\begin{tabular}{|c|c|c|c|c|c|c|c|c|c|}
\hline Age & Gender & $\begin{array}{l}\text { Educational } \\
\text { qualification }\end{array}$ & $\begin{array}{l}\text { Prior } \\
\text { computer } \\
\text { user }(\mathrm{Y} / \mathrm{N})\end{array}$ & $\begin{array}{l}\text { Prior } \\
\text { mobile } \\
\text { user }(\mathrm{Y} / \mathrm{N})\end{array}$ & $\begin{array}{l}\text { Time taken } \\
\text { by keyboard } \\
(\mathrm{Sec})\end{array}$ & $\begin{array}{l}\text { No. of mistakes } \\
\text { done while } \\
\text { keyboard using }\end{array}$ & $\begin{array}{l}\text { Time taken } \\
\text { by numeric } \\
\text { keypad (sec) }\end{array}$ & $\begin{array}{l}\text { No. of mistakes } \\
\text { done while } \\
\text { using keypad }\end{array}$ & Remarks \\
\hline 30 & $\mathrm{M}$ & $2^{\text {nd }}$ Standard & $\mathrm{N}$ & $\mathrm{Y}$ & 40 & 2 & 40 & 1 & Not able to click using mouse \\
\hline 30 & M & $3^{\text {rd }}$ Standard & $\mathrm{N}$ & $\mathrm{Y}$ & 49 & 3 & 35 & 0 & $\begin{array}{l}\text { Not able to Control the curser movement. } \\
\text { Comfortable with Numeric keypad }\end{array}$ \\
\hline 28 & M & $2^{\text {nd }}$ Standard & $\mathrm{N}$ & $\mathrm{Y}$ & 48 & 3 & 32 & 0 & ------do------- \\
\hline 37 & M & $2^{\text {nd }}$ Standard & $\mathrm{N}$ & $\mathrm{Y}$ & 51 & 2 & 40 & 1 & -------do------- \\
\hline 24 & M & $4^{\text {th }}$ Standard & $\mathrm{N}$ & $\mathrm{Y}$ & 58 & 4 & 37 & 0 & Not able to click using mouse \\
\hline 28 & M & $3^{\text {rd }}$ Standard & $\mathrm{N}$ & $\mathrm{Y}$ & 49 & 2 & 34 & 1 & Not able to click using mouse \\
\hline 31 & M & $5^{\text {th }}$ Standard & $\mathrm{N}$ & $\mathrm{Y}$ & 53 & 3 & 32 & 1 & ------do-------- \\
\hline 27 & M & $3^{\text {rd }}$ Standard & $\mathrm{N}$ & $\mathrm{Y}$ & 47 & 3 & 40 & 2 & --------do-------- \\
\hline 26 & $\mathrm{~F}$ & $6^{\text {th }}$ Standard & $\mathrm{N}$ & $\mathrm{Y}$ & 54 & 5 & 30 & 0 & $\begin{array}{l}\text { Not able to hold the mouse properly even } \\
\text { after repeated attempts and guidance }\end{array}$ \\
\hline 34 & $\mathrm{~F}$ & $2^{\text {nd }}$ Standard & $\mathrm{N}$ & $\mathrm{Y}$ & 50 & 2 & 30 & 0 & Not able to Control the curser movement \\
\hline 30 & M & $3^{\text {rd }}$ Standard & $\mathrm{N}$ & $\mathrm{Y}$ & 41 & 2 & 40 & 1 & Not able to click using mouse \\
\hline 31 & M & $3^{\text {rd }}$ Standard & $\mathrm{N}$ & $\mathrm{Y}$ & 48 & 3 & 34 & 0 & $\begin{array}{l}\text { Not able to Control the curser movement. } \\
\text { Comfortable with Numeric keypad }\end{array}$ \\
\hline 28 & M & $2^{\text {nd }}$ Standard & $\mathrm{N}$ & $\mathrm{Y}$ & 48 & 2 & 31 & 0 & 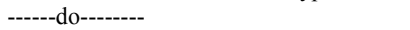 \\
\hline 38 & $\mathrm{~F}$ & $1^{\text {st }}$ Standard & $\mathrm{N}$ & $\mathrm{Y}$ & 52 & 2 & 40 & 1 & -------do------- \\
\hline 23 & M & $4^{\text {th }}$ Standard & $\mathrm{N}$ & $\mathrm{Y}$ & 60 & 4 & 38 & 0 & Not able to click using mouse \\
\hline 28 & $\mathrm{~F}$ & $3^{\text {rd }}$ Standard & $\mathrm{N}$ & $\mathrm{Y}$ & 48 & 2 & 34 & 1 & Not able to click using mouse \\
\hline 31 & M & $4^{\text {th }}$ Standard & $\mathrm{N}$ & $\mathrm{Y}$ & 53 & 3 & 32 & 1 & ------do------- \\
\hline 27 & M & $3^{\text {rd }}$ Standard & $\mathrm{N}$ & $\mathrm{Y}$ & 48 & 3 & 40 & 1 & -------do------- \\
\hline 26 & M & $6^{\text {th }}$ Standard & $\mathrm{N}$ & $\mathrm{Y}$ & 54 & 4 & 30 & 0 & $\begin{array}{l}\text { Not able to hold the mouse properly even } \\
\text { after repeated attempts and guidance }\end{array}$ \\
\hline 34 & $\mathrm{~F}$ & $2^{\text {nd }}$ Standard & $\mathrm{N}$ & $\mathrm{Y}$ & 50 & 2 & 32 & 0 & Not able to Control the curser movement \\
\hline 36 & M & $2^{\text {nd }}$ Standard & $\mathrm{N}$ & $\mathrm{Y}$ & 52 & 2 & 30 & 0 & Not able to Control the curser movement \\
\hline 34 & $\mathrm{~F}$ & $2^{\text {nd }}$ Standard & $\mathrm{N}$ & $\mathrm{Y}$ & 46 & 2 & 32 & 0 & $\begin{array}{l}\text { Not able to hold the mouse properly even } \\
\text { after repeated attempts and guidance }\end{array}$ \\
\hline 32 & M & $3^{\text {rd }}$ Standard & $\mathrm{N}$ & $\mathrm{Y}$ & 47 & 2 & 29 & 1 & Not able to Control the curser movement \\
\hline 34 & M & $4^{\text {th }}$ Standard & $\mathrm{N}$ & $\mathrm{Y}$ & 50 & 1 & 30 & 0 & Not able to Control the curser movement \\
\hline 26 & $\mathrm{~F}$ & $2^{\text {nd }}$ Standard & $\mathrm{N}$ & $\mathrm{Y}$ & 48 & 2 & 31 & 1 & -------do------- \\
\hline
\end{tabular}

\section{Pervasive Human Sensing and Remote Assistance}

Pervasive human sensing concept along with remote assistance is gaining lot of popularity in recent times and coming out of academia to the practical usage, especially in military domain (Gouin and Lavigne, 2010). This method provides live data streams, using accessories such as head-mounted cameras, to a multi-intelligence center. These deployed personnel could also benefit from virtual assistance. Using Head Mounted Device (HMDs) collaboration could take place between deployed soldiers and a military specialist in a command centre. As an example, using a bidirectional feed, the helpful inputs of a translator, military expert or medical staff can be provided to a soldier in the field to provide him on spot valuable assistance. Theses off site (remote) specialists could insert information directly into the HMD of the soldier. Local population could help soldiers on cultural and ethnic issues pertaining to his local war contexts directly from a local command center and not be seen/perceived as helping the forces.

\section{Context Sensitive/Adaptive User Interfaces}

This has been a major research focus in recent years. An adaptive user interface changes its layout and element of information based on the user roles, his needs, preferences and contexts. This provides tailoring the interface to the task at hand to be performed. Adaptive user interfaces are also used to overcome the information overload problem by focusing on the required information and processes and works as a self learning system.

\section{Emotion Recognition Multimodal Systems}

The recognition of emotion from facial expression has been the focus of a large number of psychological studies over the past several decades. In general, people are able to perceive one's emotional state based on their observations about one's face, body, eyes and voice. Research in multimodal systems have been conducted to allow the inferring of one's emotional state based on various behavioral signals. Neurobiological findings from experiments involving lesions, electroencephalography etc. provides further inputs towards emotion recognition by machines. A bimodal system based on fusing the facial recognition and acoustic information, provides higher accuracy in terms of emotion recognition of 'sadness, anger, happiness and neutral state'. In a military intelligence context, emotion recognition may provide valuable clues about a person's stress level, intent, or trust level. This can also be very important in various other applications. It is of prime importance that the interaction of humans with the computers should be latency free, thus taking it to the level of face-to-face communication.

\section{Eye Tracking}

Eye can be tracked through some detection algorithms. Eye tracking can be used to point at some point on the screen by just staring at that point. Eyetracking could be used to observe where the user is looking at and customize accordingly the user 
interface. It does not require any physical movement other than eye movement. Hence it can be considered as easiest way to point at any position on the screen. But eye tracking technology as of now is not accurate and have many technical limitations (Jacob, 1995).

\section{Conclusion}

Providing the benefits of ICT to the rural illiterate masses is a major challenge. We have discussed in this study the various requirements and design challenges towards development of HCI, specifically input devices for computer illiterates in the context of prevailing eco system in rural areas, characteristically in developing countries. We have presented the newly designed numeric keypad that satisfies the tight and at times conflicting requirements. An experiment has been conducted to assess the efficacy of the designed keypad in the intended context and compared with that of conventional keyboard and mouse. The efficiently designed numeric keypad clearly outperformedthe conventional keyboard and mouse. This work will be useful for future research towards efficient HCI design for computer illiterates in rural eco system.

\section{Author's Contributions}

All authors equally contributed in this work.

\section{Ethics}

This article is original and contains unpublished material. The corresponding author confirms that all of the other authors have read and approved the manuscript and no ethical issues involved.

\section{References}

Chang, C.L., 2008. User interface design of smalldisplay devices for the rural developing world. Master's Thesis, University of Tampere.

Czaja, S.J., N. Charness, A.D. Fisk, C. Hertzog and S.N. Nair et al., 2006. Factors predicting the use of technology: Findings from the Center for Research and Education on Aging and Technology Enhancement (CREATE). Psychol. Aging, 21: 333-353.

DeitY, 2014. DeitY.

Dutta, P., B. Aparna, B. Sridharan and V. Tyagi, 2013. Efficient marker based gesture recognition technique. Int. J. Comput. Applic., 81: 11-15.

Eshet-Alkalai, Y., 2004. Digital literacy: A conceptual framework for survival skills in the digital era. J. Educ. Multimedia Hypermedia, 13: 93-106.
Gouin, D. and V. Lavigne, 2010. Trends in humancomputer interaction to support future intelligence analysis capabilities. Proceedings of the 16th International Command and Control Research and Technology Symposium, Jun. 21-23, Quebec City, Canada, pp: 1-48.

Jacob, R.J.K., 1995. Eye Tracking in Advanced Interface Design. In: Virtual Environments and Advanced Interface Design, Barfield, W. and T.A. Furness (Eds.), Oxford University Press, New York, ISBN-10: 0195360532, pp: 258-288.

Juan, P.W., K. Mathias, S. Helman and E. Yael, 2011. Vision-based hand-gesture applications. Commun. ACM, 54: 60-70. DOI: 10.1145/1897816.1897838

Luria, A.R., 1976. Cognitive Development: Its Cultural and Social Foundations. 1st Edn., Harvard University Press, Cambridge, ISBN-10: 0674137329, pp: 175.

Manly, J.J., P. Touradji, M.X. Tang and Y. Stern, 2003. Literacy and memory decline among ethnically diverse elders. J. Clin. Exp. Neuropsychol., 25: 680-690.

Medhi, I., S. Patnaik, E. Brunskill, G.S.N. Nagasena and W. Thies et al., 2011. Designing mobile interfaces for novice and low-literacy users. ACM Trans. Comput. Human Interact., 18: 1-28.

Medhi, I., S.R. Menon, E. Cutrell and K. Toyama, 2010. Beyond strict illiteracy: Abstracted learning among low-literate users. Proceedings of the 4th ACM/IEEE International Conference on Information and Communication Technologies and Development. Dec. 13-16, London, United Kingdom, pp: 1-9. DOI: 10.1145/2369220.2369241

Nitish, R. and T.A. Unnikrishnan, 2012. Modeling of an intuitive gesture recognition system. Special Issue Int. J. Comput. Applic.

Rouse, M., 2005. ICT (information and communications technology-or technologies) definition. TechTarget.

Taveira, A.D. and S.D. Choi, 2009. Review study of computer input devices and older users. Int. J. Human Comput. Interact., 25: 455-474.

UNESCO, 2014. UNESCO.

Ul Haq, E., S.J.H. Pirzada, M.W. Baig and H. Shin, 2011. New hand gesture recognition method for mouse operations. Proceedings of the 54th International Midwest Symposium on Circuits and Systems, Aug. 7-10, IEEE Xplore Press, Seoulc, pp: 1-4. DOI: 10.1109/MWSCAS.2011.6026330

VanLinden, S. and A.H.M. Cremers, 2008. Cognitive abilities of functionally illiterate persons relevant to ICT use. Proceedings of the 11th International Conference on Computers Helping People with Special Needs, Jul. 9-11, Springer, Austria, pp: 705-712. DOI: 10.1007/978-3-540-70540-6_103 